WILL AUTONOMOUS VEHICLES UNDERMINE ONTARIO PROVINCIAL POLICIES TO CONCENTRATE JOBS AND HOUSING?

EVIDENCE FROM THE GREATER TORONTO-HAMILTON AREA

by

\author{
Tyler Olsen \\ BA, University of Toronto, 2015 \\ A Major Research Paper \\ Presented to Ryerson University \\ In partial fulfilment of the requirements for the degree of \\ Master of Planning \\ In \\ Urban Development
}

Toronto, Ontario, Canada, 2018

(C) Tyler Olsen 2018 
Author's Declaration for Electronic Submission of a MRP

I hereby declare that I am the sole author of this MRP. This is a true copy of the MRP, including any required final revisions.

I authorize Ryerson University to lend this MRP to other institutions or individuals for the purpose of scholarly research.

I further authorize Ryerson University to reproduce this MRP by photocopying or other means, in total or in part, at the request of other institutions or individuals for the purpose of scholarly research.

I understand that my MRP may be made available to the public. 


\title{
WILL AUTONOMOUS VEHICLES UNDERMINE ONTARIO PROVINCIAL POLICIES TO CONCENTRATE JOBS AND HOUSING?: \\ EVIDENCE FROM THE GREATER TORONTO-HAMILTON AREA
}

\author{
(C) Tyler Olsen 2018 \\ Master of Planning \\ In \\ Urban Development \\ Ryerson University
}

\begin{abstract}
Fully autonomous vehicles (AVs) may drastically alter the way people travel and where they choose to live and work. AVs could lead to either more dispersed or concentrated land use patterns. The concentration of employment and residences-along with travel mode emphasis on transit, cycling and walking-is a central priority for Ontario's Growth Plan for the Greater Golden Horseshoe.

This study explores responses to a 2016 survey of residents of the Greater Toronto and Hamilton Area, regarding the potential relocation of work or residence in response to AVs, to understand the locations and characteristics related and the potential impacts on land use that may result.

There is potential for high-quality shared AV service to act as a concentrating force for residences in the City of Toronto and its western and northern suburbs. But there is also potential for AVs to disrupt travel mode-based objectives, eroding pedestrian and transit use.
\end{abstract}

Key Words: Autonomous Vehicles, Land Use, Toronto 


\section{Acknowledgements}

My thanks to Professor Matthias Sweet for his supervision of this research. This paper could not have happened without his patient guidance and sage advice.

Additional thanks are due to Daniel Haufschild for offering his time, professional perspective and providing thorough, thoughtful comments as second reader.

Finally, this research owes a debt of gratitude to Kailey Laidlaw, Elyse Comeau, Leah Birnbaum, and the other members of Ryerson University's TransForm lab, for their prior work and research on this topic. 


\section{Table of Contents}

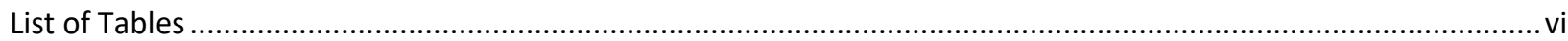

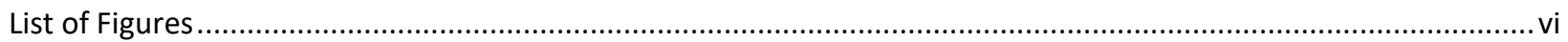

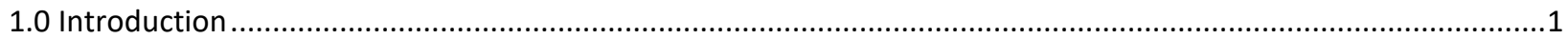

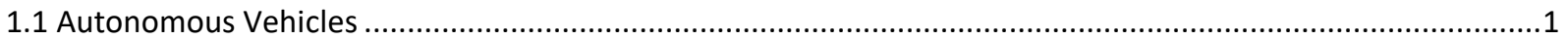

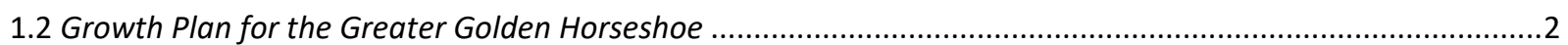

1.3 The Issue

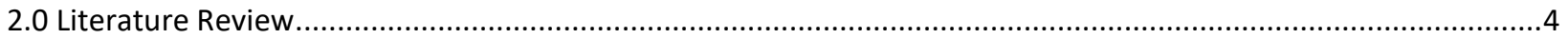

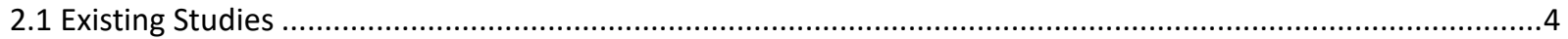

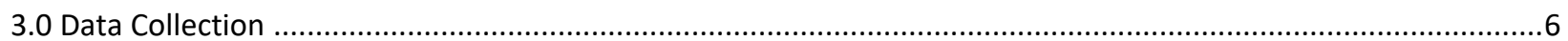

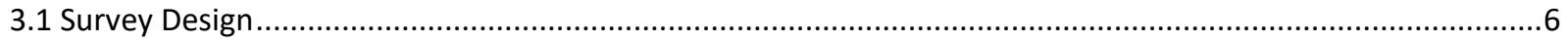

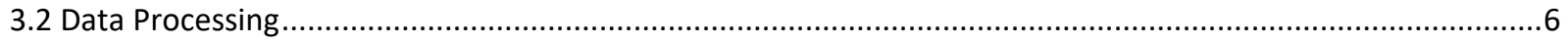

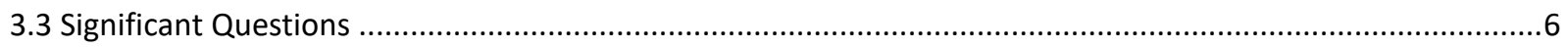

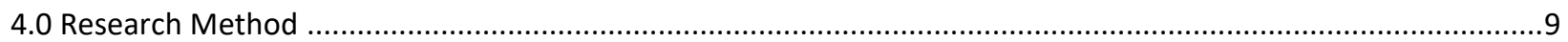

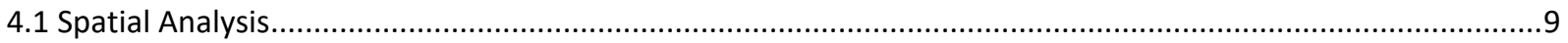

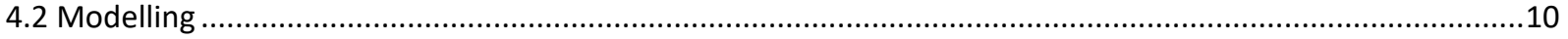

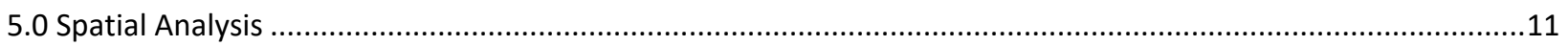

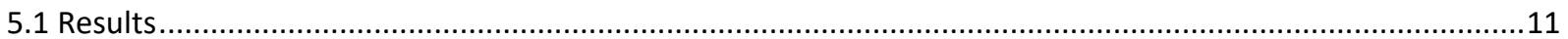

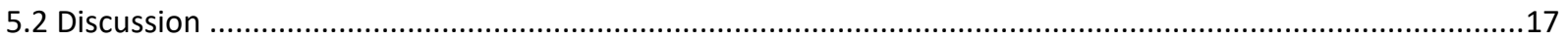

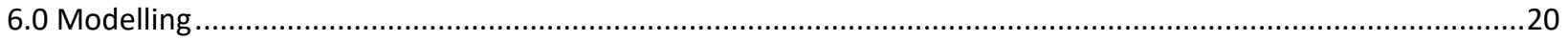

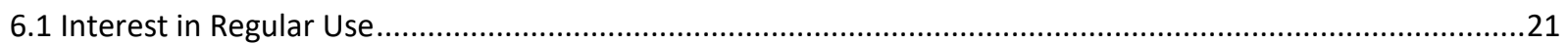

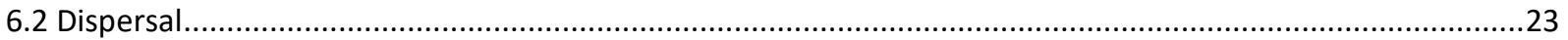

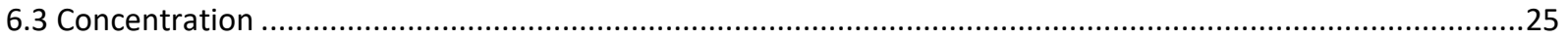

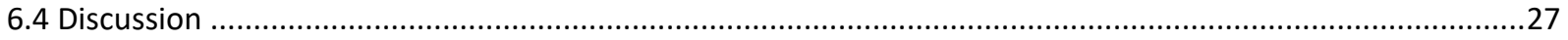

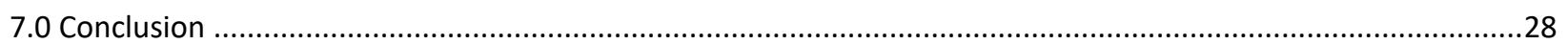

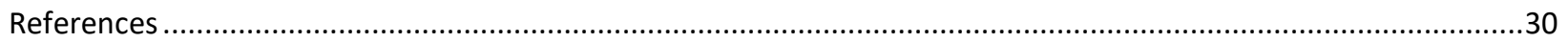




\section{List of Tables}

Table 1. Survey Respondents by GTHA Jurisdiction.................................................................................

Table 2. Moran's I Measure of Global Clustering for Responses by Residential Location .....................................12

Table 3. Moran's I Measure of Global Clustering for Responses by Work Location ...............................................12

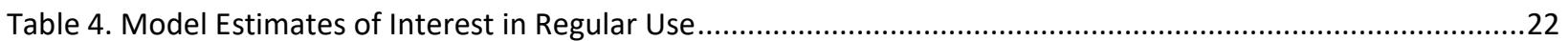

Table 5. Model Estimates of Likelihood to Travel Further at Same Speed (Model II) and Faster Speed (Model III) ...24

Table 6. Model Estimates of Attraction to High SAV Service Neighbourhoods .................................................26

\section{List of Figures}

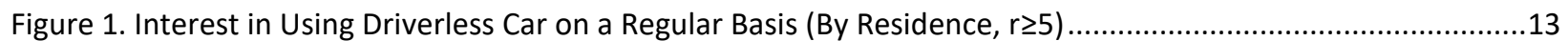

Figure 2. Interest in Using Driverless Car on a Regular Basis (By Residence, $r \geq 10$ ) ..........................................14

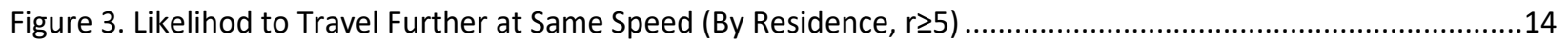

Figure 4. Likelihod to Travel Further at Faster Speed (By Residence, $r \geq 5$ ) ....................................................15

Figure 5. Attraction to High SAV Service Neighbourhoods (By Residence, $r \geq 5$ ) ..........................................15

Figure 6. Attraction to High SAV Service Neighbourhoods (By Residence, $r \geq 10$ ) ..............................................16

Figure 7. Attraction to High SAV Service Neighbourhoods (By Workplace, $r \geq 10)$.........................................16 


\subsection{Introduction}

\subsection{Autonomous Vehicles}

Automated vehicle technology is already commercially available and bodes a future that reduces the need for and stress of human driving. A range of driver-assist technologies are increasingly available from numerous automakers. Fully autonomous vehicles (hereon referred to as AVs) are those not requiring a driver at all and are the most advanced form of vehicle automation. These vehicles are still in development, but are predicted to reach capability for initial commercial use on public roads within as little as two years. Further capabilities for general consumer use and mass production are expected to precipitously expand the technology's adoption and use over the 2020s-2030s (Litman, 2015; Zon \& Ditta, 2016; Bloomberg Philanthropies \& The Aspen Institute, 2017; SSCTC, 2018).

Once they do arrive, AVs have the potential to drastically alter the way people travel and where people choose to live and work. This could in turn have impacts, positive and negative, on economies, cities and daily life. Most starkly, many expect AVs could lead to either more dispersed or compact land use patterns.

Dispersion could arise from AVs eliminating the attentive burden of driving, freeing up in-vehicle time for other activities-productive or leisurely-and thereby reducing the generalized cost of travel. Further, if the technology, as predicted, proves to reduce collisions and necessary buffer distances between vehicles, road speeds and capacity may increase. Faster travel speeds and reduced cost of travel reduces the burden of distance. Lessons from past automobile-based mobility improvements suggest that reduced transportation costs often lead to increased disconnection of home and work and, thus, dispersed land use patterns. It may also make higher paying but formerly too distant employment more attractive. In this way, AVs may encourage longer commutes and a dispersal of job location from home location (Anderson et al., 2014; Bansal et al., 2016; Milakis et al., 2017).

Alternately, AVs may make concentrated urban settings more attractive by providing additional transportation choice within dense and high-amenity urban neighbourhoods. Density offers advantages for ridesharing through a larger internal market of trip origins and destinations, enhancing economies of scale and service frequency, and thereby increasing quality of service and decreasing costs (Loeb et al., 2018; Milakis et al., 2017). AVs' potential for more effectively coordinated ridesharing or connecting to transit may attract people to areas of existing employment and residential concentration, drawn by the service advantages that these dense, high-activity areas may offer. AVs may also reduce the need for land dedicated to parking, allowing for infill of additional residential or employment uses. As such, AVs could promote further colocation and concentration of employment and residence (Anderson et al., 2014; Bansal et al., 2016; Milakis et al., 2017).

AV technology is closely intertwined with other emerging technologies and business models in transportation, known collectively as "new mobility." This includes electric-powered vehicles and connected vehicle technology, 
which allows vehicles to communicate with each other and with infrastructure, enabling more effective coordination. On-demand ridesharing (such as Uber) and membership-based vehicle fleet sharing may provide a compelling alternative to owning an individual, private vehicle and make travel by AV possible for those unable to afford the relatively high upfront costs of AV technology. AVs' ability to "drive themselves" between users greatly enhances the capability of these business models (WSP, 2017).

So it is not strictly a matter of AV technology in isolation, but its connection to and application through these other "new mobility" elements that will ultimately determine consumer use and AVs broader impacts on society. For governments, this presents a route to affect the outcomes of AV technology through regulation and collaboration in the sphere of these additional emerging technologies and business models (WSP, 2016).

\subsection{Growth Plan for the Greater Golden Horseshoe}

Originally released by the Government of Ontario in 2006, the Growth Plan for the Greater Golden Horseshoe (GPGGH) marked a new era in planning for the Toronto region, the first regional plan for the area in nearly thirty years (White, 2007, 44).

The GPGGH was a response to intensifying growth pressures, an increasingly distant suburban fringe, intensifying traffic congestion, growing public environmental consciousness, and serious strains on public funds to service the rapid pace of greenfield development. The GPGGH calls for "complete communities that are compact, transit supportive and make effective use of investments in infrastructure and public service facilities" (MMA, 2017, 5) and "a land use pattern that encourages the efficient use of land, walkable neighbourhoods, mixed land uses (residential, retail, workplace, and institutional) all within one neighbourhood, proximity to transit and reduced need for infrastructure" (MMA, 2017, 69). This seeks to have the co-location of residential and employment land uses in increasing density and proximity to each other, "redirect[ing] development from the urban edge into existing urban areas" (White, 2007, 5). There is additionally a clear emphasis on a travel mode shift away from private automobile use towards transit, cycling and walking (Courtney, 2009, 81).

The plan underwent review and update in 2017, but the core of the original plan remains intact and a keystone of Ontario's current planning framework. The concentration of employment and residences remains a central priority for land use and transportation planning in the Toronto region through the GPGGH (Courtney, 2009; Newbold \& Scott, 2013; Allen \& Campsie, 2013). These principles guide private development capital and direct the investment of public infrastructure funds, both very substantial expenditures. However, by their very nature, these long-term sunk costs cannot be easily rearranged if confronted with unexpected change, creating the potential for tremendous waste if actual outcomes do not fall in line with the expectations of the plan. 


\subsection{The Issue}

Are AVs likely to induce dispersion of work and home locations, undermining the Province of Ontario's policy objectives that are premised on concentrating the two together? This is critical because, if AVs do result in a tendency towards dispersal of work and home, there is potential for a severe and costly spatial mismatch of current planning efforts and infrastructure projects based on the GPGGH with the future population's location and travel choices.

Though often framed as a dichotomy of dispersal or concentration, the outcome could be some balance of both trends, with net results ultimately being the aggregate of local users' responses to regulation and the technology. Recognizing for whom and under which conditions either of these land use outcomes might result is essential if interactions of transportation and land use are to be utilized for public benefit. However, this depends on the particulars of specific jurisdictions and populations. For the GPGGH and other elements of Ontario's planning framework to be effective it should have an inherent understanding of its relevant public in light of this new technology. 


\subsection{Literature Review}

\subsection{Existing Studies}

Evidence is still emerging regarding the potential impacts of AVs. Given that AVs are not yet a part of existing traffic streams in significant numbers, traditional methods of transportation modelling, based on using existing travel patterns to predict future travel behaviour and demand, are not a viable option. Instead, studies of the public's attitudes and stated preferences regarding intent to use AVs are needed to serve as a basis for predicting future outcomes (Zmud et al., 2016).

Direct study of particular places and populations are required to make reliable local predictions. Of course, observations from one jurisdiction may not necessarily be generalizable to another. Additionally, observations in one place are subject to change over time. AVs are not yet fully developed and are relatively unfamiliar to many people. With time, further technological development and the proliferation of information could change individuals' views.

At the time of writing, empirical studies of the public in regards to AVs mostly draw from the American or other international (non-Canadian) contexts (Begg, 2014; Schoettle \& Sivak, 2014; Kyriakidis, 2015; Bansal et al. 2016; Krueger et al., 2016; Zmud et al., 2016; Bansal \& Kockelman, 2017; Lustgarten \& Le Vine, 2017).

Of particular relevance, Schoettle and Sivak (2014) conducted an online survey of the attitudes and opinions of individuals from the United States, the United Kingdom, Australia, China, India and Japan. In all countries, a majority of respondents expressed positive interest to have access to AV technology.

Zmud et al. (2016) performed an online survey of Austin, Texas residents, followed up with focus groups. Psychosocial factors, including technology adoption, privacy concerns and perceptions of safety were found to be the most crucial predictors of AV acceptance. Notably, demographic variables such as gender and age were not found to be as important. It was also found that most respondents did not anticipate that their travel behaviour or residential location would substantially change in response to AVs.

Bansal et al. (2016) surveyed 347 Austin, Texas residents. Modelling work that followed investigated the impact of demographic, built-environment, and travel behaviour variables on willingness to pay for AVs as well as the impact of AVs on home-location-shift decisions. "[M]ale respondents, with a greater number of children, living in higherincome neighbourhoods, who drove alone on social trips" (p. 8) all else being equal, were found to have the highest willingness to pay to have fully automated capability in their next vehicle. "[R]espondents with a greater number of children, living farther from their workplace in high employment density neighbourhoods, and who drive alone for work trips" (p. 12) as well as "[p]eople with Bachelors degrees or higher, living in high household density neighbourhoods"(p. 12) were predicted to disperse further from central Austin. "[F]ull-time working males 
with higher [household income] and higher [vehicle miles travelled]" (p.12) were likelier to shift closer to the concentrated density of central Austin.

Lavasani et al. (2017) developed models of willingness to pay and potential for relocation through an online survey of students, faculty and staff at four Florida universities. Higher willingness to pay values were observed for the young $(<30)$, males and long-distance commuters. Experience with auto collisions and recent purchase of a new vehicle generally decreased willingness to pay. A greater willingness to relocate was observed in males, lowincome households and the drivers in carpool arrangements. Greater household size and greater number of drivers in the family negatively affected willingness to relocate.

In order to similarly inform predictions for the Toronto region, there is a need for direct study of the local population. Olsen, Laidlaw and Sweet (2018) conducted such a study in 2016, through online survey and focus groups, regarding public opinion and consumer preferences on AVs. This data so far has yielded an initial analysis of public opinion and models estimating willingness to pay, personal AV adoption and future market share (Laidlaw \& Sweet, 2017; Birnbaum et al., 2017; Laidlaw et al., 2018; Olsen et al., 2018). However this data has yet to be fully analyzed regarding the potential for relocation in response to AV technology. 


\subsection{Data Collection}

\subsection{Survey Design}

Through Ryerson University's Transportation and Land Use Planning Research Laboratory (TransForm), an online survey was conducted in November, 2016. 3201 adults in the Greater Toronto and Hamilton Area (GTHA), between 18 and 75 years old, answered questions about their demographic characteristics, household qualities, employment, travel and commuting patterns, and attitudes. They also provided stated preference responses in regards to how they anticipate they would adopt, use and respond to AV technology. Recruitment was drawn from a pool of participants accessed through Research Now, a private survey consultant.

To ensure reasonable representation of the regional population, the survey was administered with target numbers for respondents from each of the GTHA's two cities and the four regional government jurisdictions in rough proportion to their regional population shares. All targets were met, with respondent numbers listed in Table 1:

Table 1. Survey Respondents by GTHA Jurisdiction

\begin{tabular}{|c|c|}
\hline Jurisdiction & Respondents \\
\hline Durham Region & 400 \\
\hline Halton Region & 300 \\
\hline City of Hamilton & 300 \\
\hline Peel Region & 500 \\
\hline City of Toronto & 1200 \\
\hline York Region & $501 *$ \\
\hline
\end{tabular}

*One additional participant beyond the target (500) was collected for York Region

\subsection{Data Processing}

Following the survey, observations were weighted (mean=1) based on the individual respondent's age group (1834, 35-55, 56-75), gender (male or female) and jurisdiction of residence (Durham, Halton, Hamilton, Peel, Toronto, York) to align with the proportions in Statistics Canada's 2016 census. Census data did not have an allocation for non-binary gender, an option present in the GTHA survey. It was necessary to randomly assign respondents identifying as non-binary to male or female for the purposes of weighting the data.

\subsection{Significant Questions}

Of particular interest to this research, the survey queried respondents with four questions on the following topics:

\section{$\underline{\text { Interest in Regular Use of AVs }}$}

I. Would you be interested in using a driverless car on a regular basis? 
In the first case, interest in regular use of a driverless car could provide insight into the potential of particular locations to be affected by driverless cars, without much further indication as to what the specific impact may be. Potential responses to the question were on a five-point scale ("very interested", "somewhat interested", "unsure", "somewhat uninterested", and "very uninterested"). There were $52 \%$ of respondents that indicated some level of positive interest. Note that this question intentionally did not specify whether the vehicle is an individually owned private autonomous vehicle (PAV) or an on-demand service shared autonomous vehicle (SAV), akin to Uber. So the question really just represents a raw affinity to the autonomous technology, without much depth as to how it may be used. Locations with greater average interest may be disposed to have higher rates of early adoption and higher rates of adoption in the longer term. It is critical that this indication is seen only as a potential because there are numerous intervening factors beyond interest in determining AV use, adoption and impact-cost and ability to pay, for instance.

\section{Likelihood to Travel Further Due to AVs}

II. Suppose using a driverless vehicle does not enable you to go faster, but enables you to now use that travel time for other activities while traveling. Would you be likely to travel further to work (e.g. for a better job or less expensive housing)?

III. Suppose using a driverless vehicle increases your commuting speed by $25 \%$ and also enables you to now use that time commuting for other activities while traveling. Would you be likely to travel further to work (e.g. for a better job or less expensive housing)?

In this case, likelihood to travel further under different speed conditions could be used to indicate employment and residential locations that are likely to experience dispersal with the arrival of AV technology. Potential responses were yes, no and unsure. Overall $31 \%$ of respondents replied affirmatively when presented with travelling at current speeds, $38 \%$ under a faster speed. The question is premised on respondents undertaking more spatially distant commutes. There is potential for "further" to be understood in terms of the alternate, less common meaning of "further" in time. But as long as travel speeds are maintained or increased, which are the conditions offered in both versions of the question, then a further commute-whether in terms of time or distance-would necessarily have to involve a change in location of employment and/or residence.

Again, this question has to be seen as a matter of potential for relocation - a willingness to consider changing the location of work or home. Presumably, actually acting to relocate would at least depend further on benefits and cost-savings that such a change would actually offer-such as a better job or less expensive housing-if not other matters of personal psychology and habit. Accordingly, responses indicating likelihood to relocate have to be understood to indicate only a potential for dispersal at both home and work locations, though the ultimate impact will rely on further factors relating to the specific circumstances of employment and residence. 
The "travel further" questions were only asked of those that indicated they were willing to purchase a PAV-that is, those that did not respond that they were totally unwilling to purchase a PAV in any of a series of preliminary questions. Accordingly, in collecting responses-which are ultimately about whether changes in travel behaviour that lead to relocation can be expected-those that indicated absolute unwillingness to purchase an autonomous vehicle, but were consequently not asked the "travel further" set of questions, can still be inferred to have indicated some level of unwillingness to change travel behaviour in response to AVs. These respondents were thus considered to have responded "no" to the "travel further" questions.

In other words, the "travel further" questions themselves were not about travelling further in a PAV specifically, but the question was only asked of those that were in some way willing to purchase a PAV. This leaves out the possibility that the user might not purchase a PAV, but still might be willing to use an SAV and might then still choose to travel further. As such, results regarding the possibility towards dispersal should be interpreted cautiously.

As a final insight, the difference between the two "travel further" questions-one in a scenario where commuting occurs at the same speed as currently, another where commuting occurs at a greater speed-the difference observed between the two may be indicative of potential to disperse, but only if AVs are able to travel at a higher rate of speed, due to more permissive speed regulations or due to more efficient roadway function and less congestion.

\section{Attraction to Neighbourhood with High-Quality SAV Service}

IV. If some of the GT[H]A's neighborhoods had access to low-cost, near-immediate, and reliable Uber-style shared driverless vehicle services (like taxis), would such a service make a neighborhood more attractive to you?

In the final case, attraction to neighbourhoods with high SAV service may be indicative of a potential to maintain or enhance existing concentrations of employment and residences, due to the advantage that dense, mixed-use areas are believed to offer in terms of economies of scale and service frequency. Options for responses were "yes", "no", and "unsure". Overall 35\% of respondents indicated increased attraction to such neighbourhoods. Of course, this depends on factors beyond the scope of the question, such as home prices, employment availability and other individual circumstances that may constrain relocating and travel decisions. Still the question highlights potential for spatial concentration to persist or intensify for particular populations, contingent on highly effective, local SAV operations being made available. Further, while there may be potential for concentration, it does not necessarily imply concentration in the current neighbourhood. It may, in fact, lead to an outflow of interested people from identified locations to other areas with more favorable SAV service. Overall, though, identified populations would theoretically be inclined to enhancing the general principle of concentrated land use. 


\subsection{Research Method}

This study explores the responses to those four significant questions, to understand potential impacts on land use that may result from AVs. First, it spatially analyzes responses based on place of residence and place of work to see whether particular areas are more prone to dispersal or concentration responses than others. Then, predictors of these responses are modelled to understand what may motivate these responses and what additional effects might accompany outcomes based on these responses.

Overall, this study is intended to be an initial exploration of the data available. Its findings are not definitive, only indications of potential towards dispersal and concentration, based on the stated preference survey responses. Further research is needed to more fully understand the findings.

\subsection{Spatial Analysis}

The survey requested that all respondents provide the postal forward sortation area code (FSA) of their place of residence and, if employed, place of work. Using this descriptor, respondents were aggregated by both work and residential FSA, for the purpose of mapping.

Mapping at the scale of FSAs was selected as this provided the greatest spatial precision from the available survey data. However, one significant issue with mapping at this scale was that many outer urban, sparsely populated FSAs did not provide many responses. This undermines the validity of response averages of those districts. Accordingly, results were analyzed at particular minimum thresholds of response totals within each FSA ( $r \geq 5$, $r \geq 10)$.

Statistics Canada's spatial data for FSA boundaries from 2011 was used, due to unavailability of 2016 data at the time of analysis. This eliminated roughly 41 respondents (30 FSAs) from being spatially analyzed by workplace, as their 2016 workplace FSAs did not exist in the 2011 dataset. However, a sample by workplace of 2055 individuals (out of a total 2096 employed) still remained, providing a substantial basis for analysis.

Using ArcGIS software, the responses were mapped, aggregated separately by work and residential FSA. Interest in regular use of automated vehicles was mapped in terms of the proportion of those in the FSA that indicated some level of interest, responding either "very interested" or "somewhat interested". Likelihood to travel further was mapped in terms of the proportion of those in the FSA that indicated likelihood to travel further at the same speed (responding "yes") and those that indicated the same for travelling further at a faster speed. Finally, attraction to locate in a high SAV service neighbourhood was mapped in terms of proportions in the FSA that responded "yes" to the question of attraction. 
ArcGIS has a suite of spatial analysis tools for further assessment of the data, once mapped. Two were employed to investigate potential spatial significance in the responses, exploring which areas seem to be more or less prone to dispersal or concentration.

The spatial autocorrelation tool was employed to obtain the Moran's I measure. This calculates the extent to which, as a whole, the data displays characteristics of clustering. Following this global analysis, the hot spot analysis tool was used to calculate the Getis Ord Gi* measure. This analyzes the specific locations in which clustering occurs and allows them to be visualized on a map.

\subsection{Modelling}

Inferential modelling was then deployed to look deeper at the inner workings of the potential relocation responses, exploring the characteristics of consumers most inclined to make new residential or work location choices in response to AVs. Using R statistical software, predictors of the four major questions of interest were estimated.

Potential predictors of these outcomes, selected for inclusion in models, involve major factors that could be reasonably expected, a priori, to be significant-though may not turn out to be significant and then still remain included for reference purposes - as well as all other unexpected factors in the survey that were found through modelling to be significant. Analysis was limited to individual factors that were gathered through the survey or area-specific factors that were available in external data sources, sorted by FSA. This includes current travel behaviour and local land use patterns. Some promising avenues of analysis were not pursued (analysis by ethnicity, immigration status, neighbourhood housing price), but remain open for further research, pending the availability of data.

Modelling was performed using a subset of the survey respondents. Specifically, only the responses of employed commuters-working full-time or part-time and not exclusively from home-were included. This was because only those that were employed were able to provide a work FSA, enabling analysis here of work location-related factors. As well, only those that regularly commuted were asked about their typical commute mode and duration, which, again, was a set of factors of particular interest. The size of this subset was 2068 out of 3201 total respondents, a still substantial sample size. 


\subsection{Spatial Analysis}

The findings of the spatial analysis - using spatial autocorrelation and local hot spot techniques - are in the following section. First the results of the techniques are presented. Then a discussion, which draws out the meaning of those results, follows.

\subsection{Results}

Spatial autocorrelation measures the extent to which, as a whole, the data displays characteristics of clustering. It calculates a Moran's I index, measuring the extent to which data shows a spatial arrangement, falling between -1.0 (dissimilar values tend to locate near each other) and +1.0 (similar values tend to locate near each other). Then, a $\mathrm{p}$-score is calculated for each dataset, indicating the extent to which the pattern observed is not due to random chance. If it is significant, the $z$-score indicates the nature of the pattern. A positive $z$-score, indicates clustering (high or low values locating near similar values). A negative z-score indicates dispersal (similar values locating away from each other) (ESRI, 2017b). The results are presented in the tables below. 


\begin{tabular}{|c|c|c|}
\hline & $r \geq 5$ & $r \geq 10$ \\
\hline $\begin{array}{l}\text { Interest in Using Driverless } \\
\text { Cars on a Regular Basis }\end{array}$ & $\begin{array}{c}\text { Clustered } \\
\text { Moran's Index: } 0.058871 \\
\text { z-score: } 7.105500 \\
\text { p-value: } 0.000000 \\
\text { FSAs: } 202\end{array}$ & $\begin{array}{c}\text { Clustered } \\
\text { Moran's Index: } 0.063138 \\
\text { z-score: } 4.095432 \\
\text { p-value: } 0.000042 \\
\text { FSAs: } 150\end{array}$ \\
\hline $\begin{array}{l}\text { Likelihood to Travel Further } \\
\text { at Same Speed }\end{array}$ & $\begin{array}{c}\text { Random } \\
\text { Moran's Index: } 0.007538 \\
\text { z-score: } 1.392798 \\
\text { p-value: } 0.163681 \\
\text { FSAs: } 202\end{array}$ & $\begin{array}{c}\text { Random } \\
\text { Moran's Index: }-0.007850 \\
\text { z-score: }-0.066689 \\
\text { p-value: } 0.946829 \\
\text { FSAs: } 150\end{array}$ \\
\hline $\begin{array}{l}\text { Likelihood to Travel Further } \\
\text { at Faster Speed }\end{array}$ & $\begin{array}{c}\text { Clustered } \\
\text { Moran's Index: } 0.009915 \\
\text { z-score: } 1.658233 \\
\text { p-value: } 0.097270 \\
\text { FSAs: } 202\end{array}$ & $\begin{array}{c}\text { Random } \\
\text { Moran's Index: }-0.003088 \\
\text { z-score: } 0.212315 \\
\text { p-value: } 0.831862 \\
\text { FSAs: } 150\end{array}$ \\
\hline $\begin{array}{l}\text { Attraction to High SAV } \\
\text { Service Neighbourhood }\end{array}$ & $\begin{array}{c}\text { Clustered } \\
\text { Moran's Index: } 0.055263 \\
\text { z-score: } 6.693800 \\
\text { p-value: } 0.000000 \\
\text { FSAs: } 202\end{array}$ & $\begin{array}{c}\text { Clustered } \\
\text { Moran's Index: } 0.089647 \\
\text { z-score: } 5.643227 \\
\text { p-value: } 0.000000 \\
\text { FSAs: } 150\end{array}$ \\
\hline
\end{tabular}

Table 3. Moran's I Measure of Global Clustering for Responses by Work Location

\begin{tabular}{|c|c|c|}
\hline & $r \geq 5$ & $r \geq 10$ \\
\hline $\begin{array}{l}\text { Interest in Using Driverless } \\
\text { Cars on a Regular Basis }\end{array}$ & $\begin{array}{c}\text { Random } \\
\text { Moran's Index: } 0.005304 \\
\text { z-score: } 0.880826 \\
\text { p-value: } 0.378412 \\
\text { FSAs: } 159\end{array}$ & $\begin{array}{c}\text { Random } \\
\text { Moran's Index: } 0.037689 \\
\text { z-score: } 0.699832 \\
\text { p-value: } 0.484032 \\
\text { FSAs: } 73\end{array}$ \\
\hline $\begin{array}{l}\text { Likelihood to Travel Further } \\
\text { at Same Speed }\end{array}$ & $\begin{array}{c}\text { Random } \\
\text { Moran's Index: }-0.007798 \\
\text { z-score: }-0.111233 \\
\text { p-value: } 0.911432 \\
\text { FSAs: } 159\end{array}$ & $\begin{array}{c}\text { Random } \\
\text { Moran's Index: } 0.069253 \\
\text { z-score: } 1.132493 \\
\text { p-value: } 0.257427 \\
\text { FSAs: } 73\end{array}$ \\
\hline $\begin{array}{l}\text { Likelihood to Travel Further } \\
\text { at Faster Speed }\end{array}$ & $\begin{array}{c}\text { Random } \\
\text { Moran's Index: }-0.006330 \\
\text { z-score: }-0.000089 \\
\text { p-value: } 0.999929 \\
\text { FSAs: } 159\end{array}$ & $\begin{array}{c}\text { Random } \\
\text { Moran's Index: } 0.001005 \\
\text { z-score: } 0.201502 \\
\text { p-value: } 0.840306 \\
\text { FSAs: } 73\end{array}$ \\
\hline $\begin{array}{l}\text { Attraction to High SAV } \\
\text { Service Neighbourhood }\end{array}$ & $\begin{array}{c}\text { Clustered } \\
\text { Moran's Index: } 0.027953 \\
\text { z-score: } 2.600511 \\
\text { p-value: } 0.009309 \\
\text { FSAs: } 159\end{array}$ & $\begin{array}{c}\text { Clustered } \\
\text { Moran's Index: } 0.185959 \\
\text { z-score: } 2.721777 \\
\text { p-value: } 0.006493 \\
\text { FSAs: } 73\end{array}$ \\
\hline
\end{tabular}


Hot spot analysis identifies specific locations in which clustering occurs and allows them to be visualized on a map. Where values of neighbouring areas are significantly higher than overall, the tool marks a hot spot-with varying levels of statistical significance, indicating the confidence that the elevated values are not due to random chance. Where values of neighbouring areas are significantly lower than overall, it marks cold spots - again with varying levels of significance. Different mathematical approaches mean that the Getis Ord Gi* results can sometimes differ from Moran's I (ESRI, 2017a). The hot spot maps produced that indicated significant results are presented below.

Figure 1

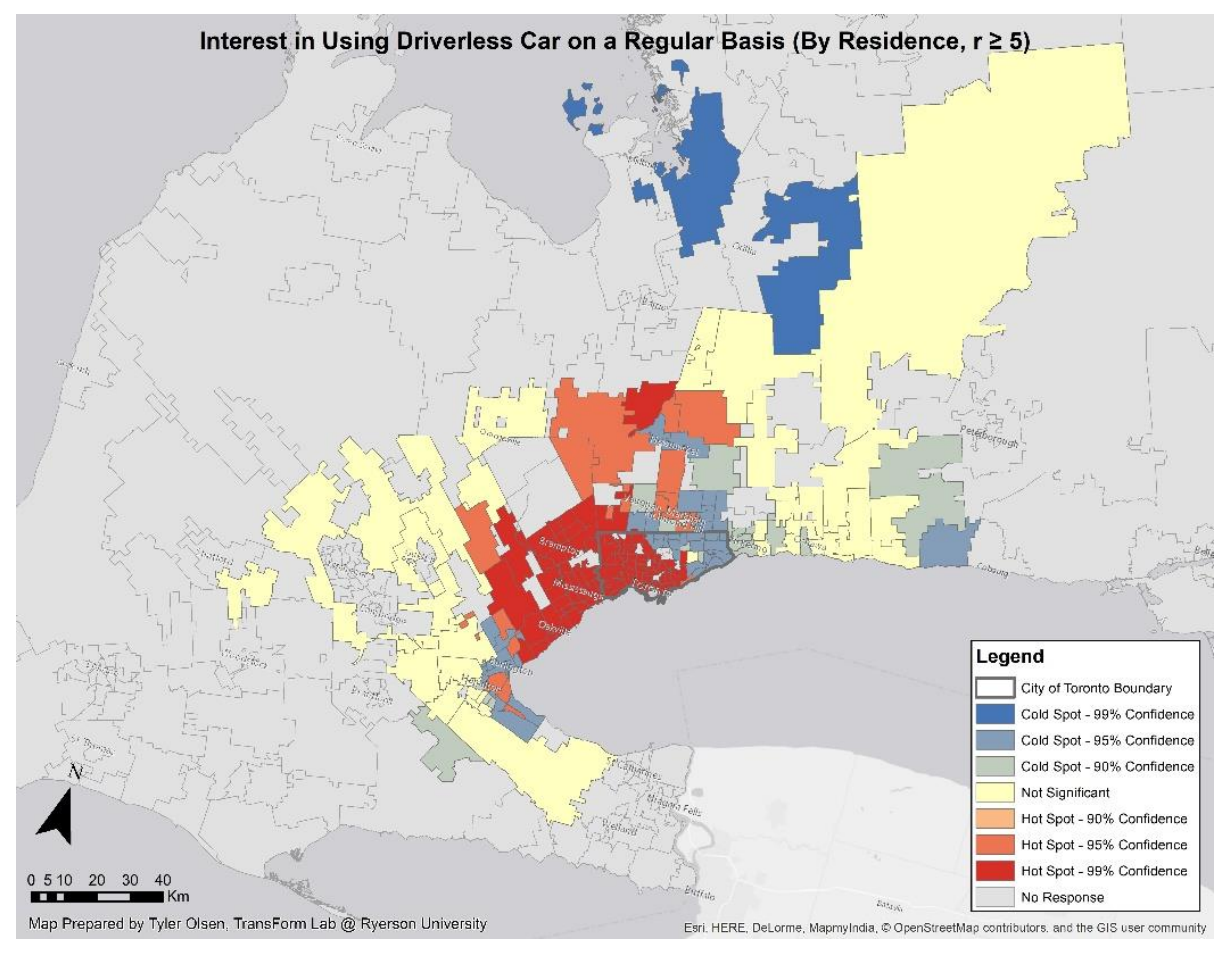


Figure 2

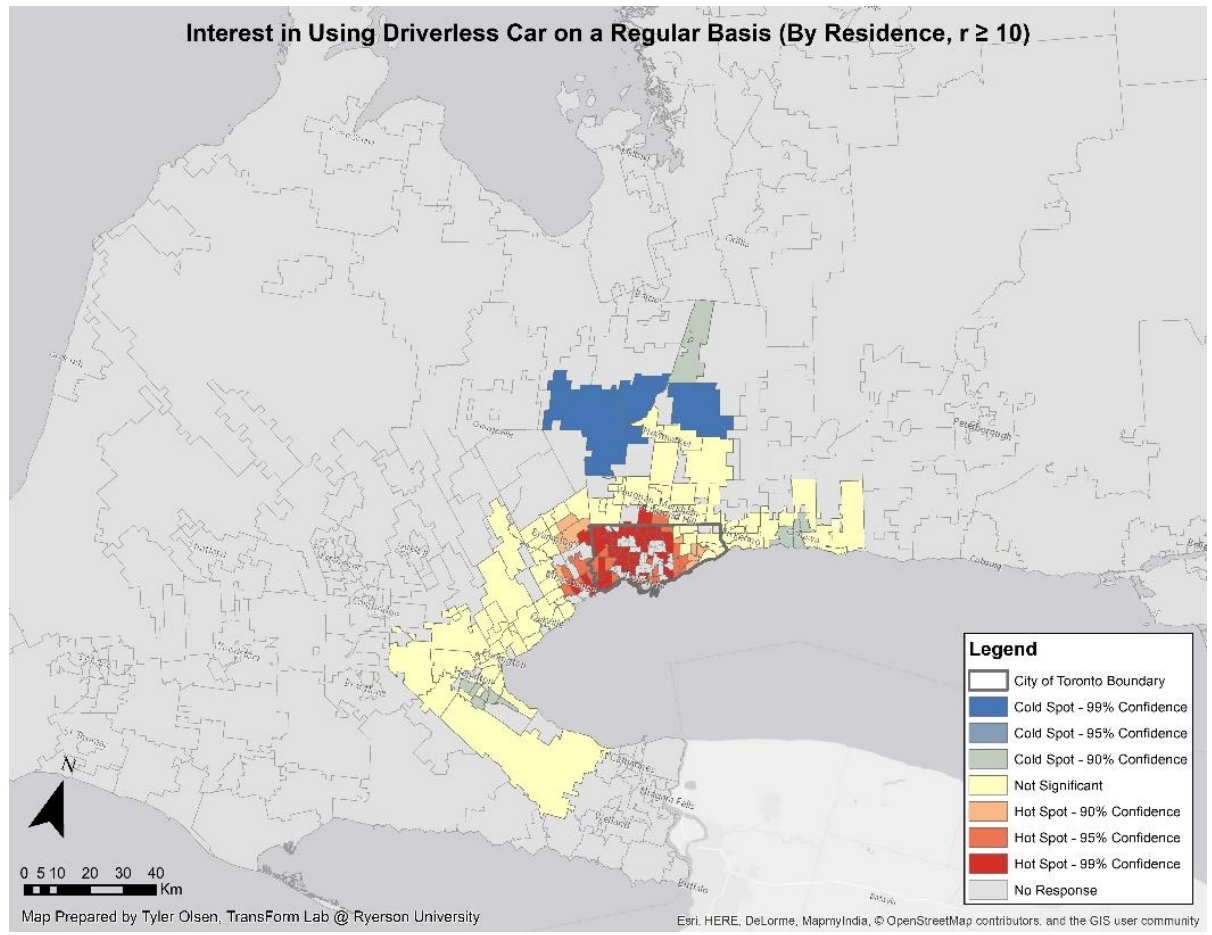

Figure 3

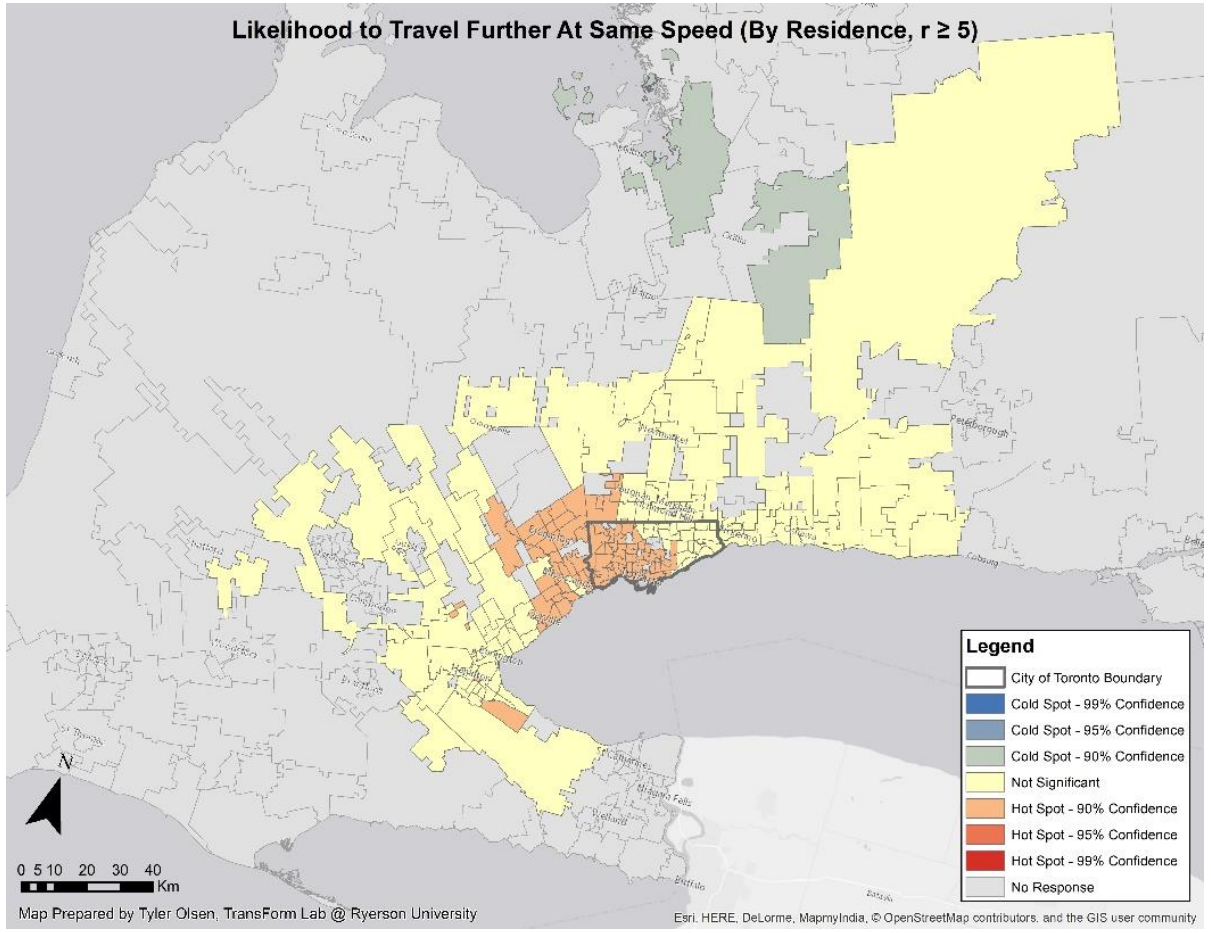


Figure 4

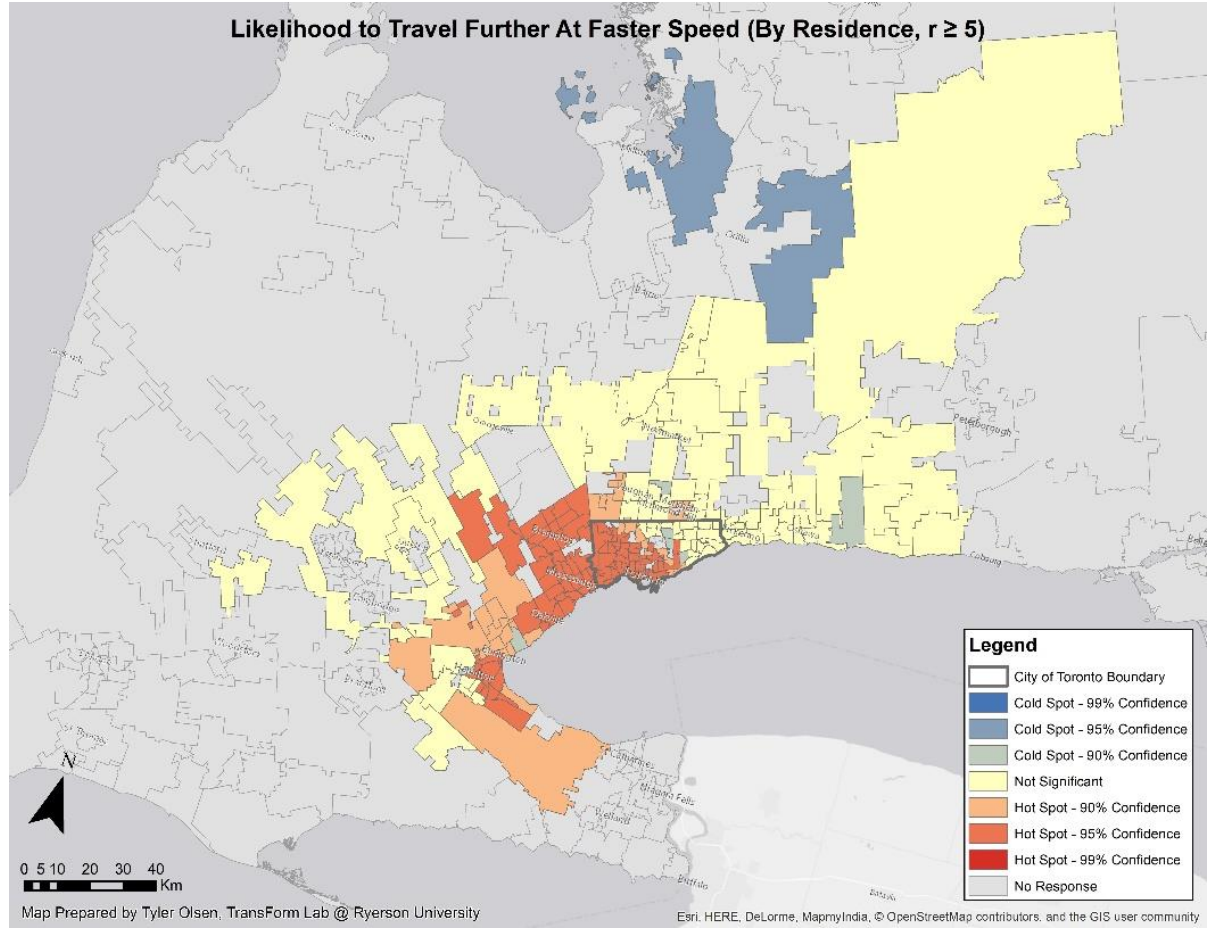

Figure 5

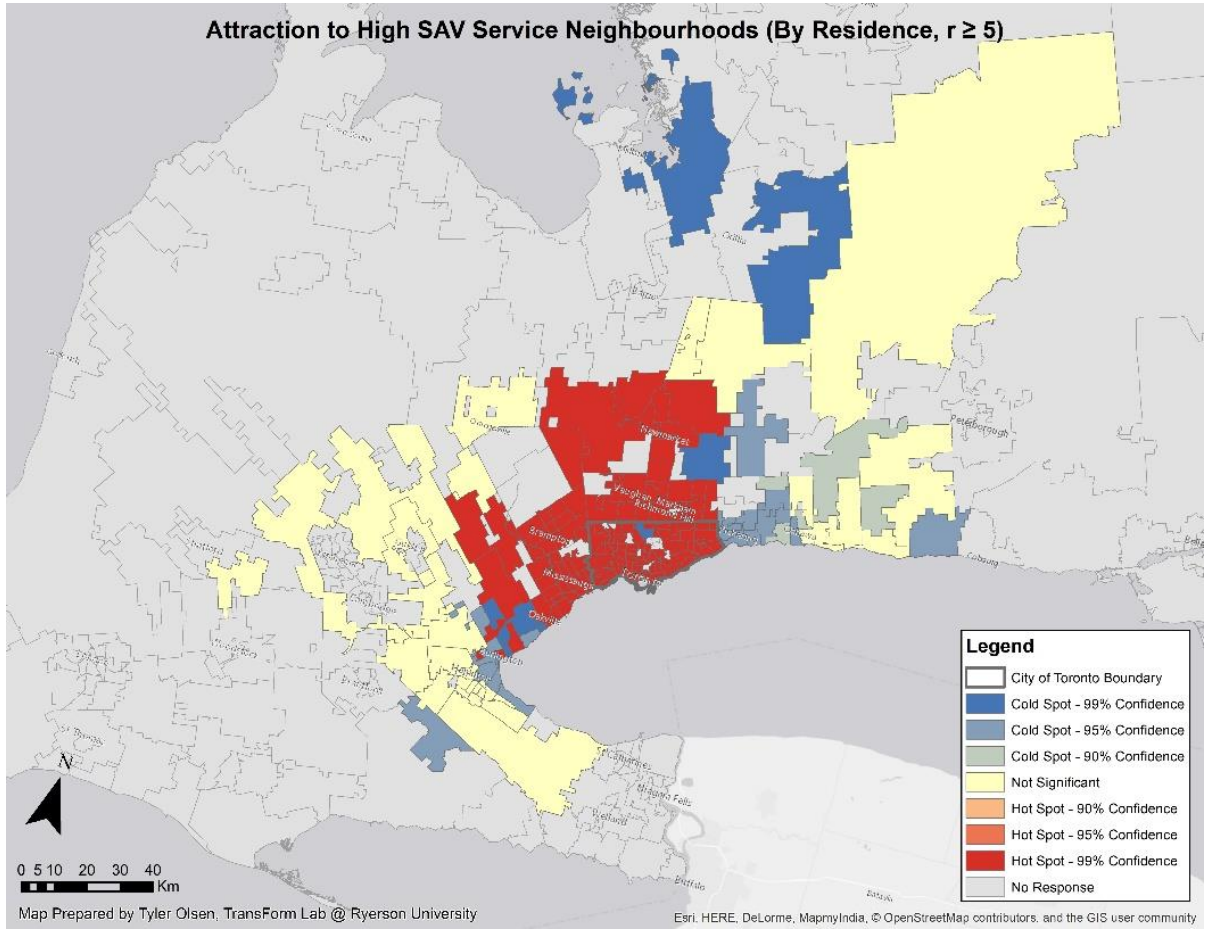


Figure 6

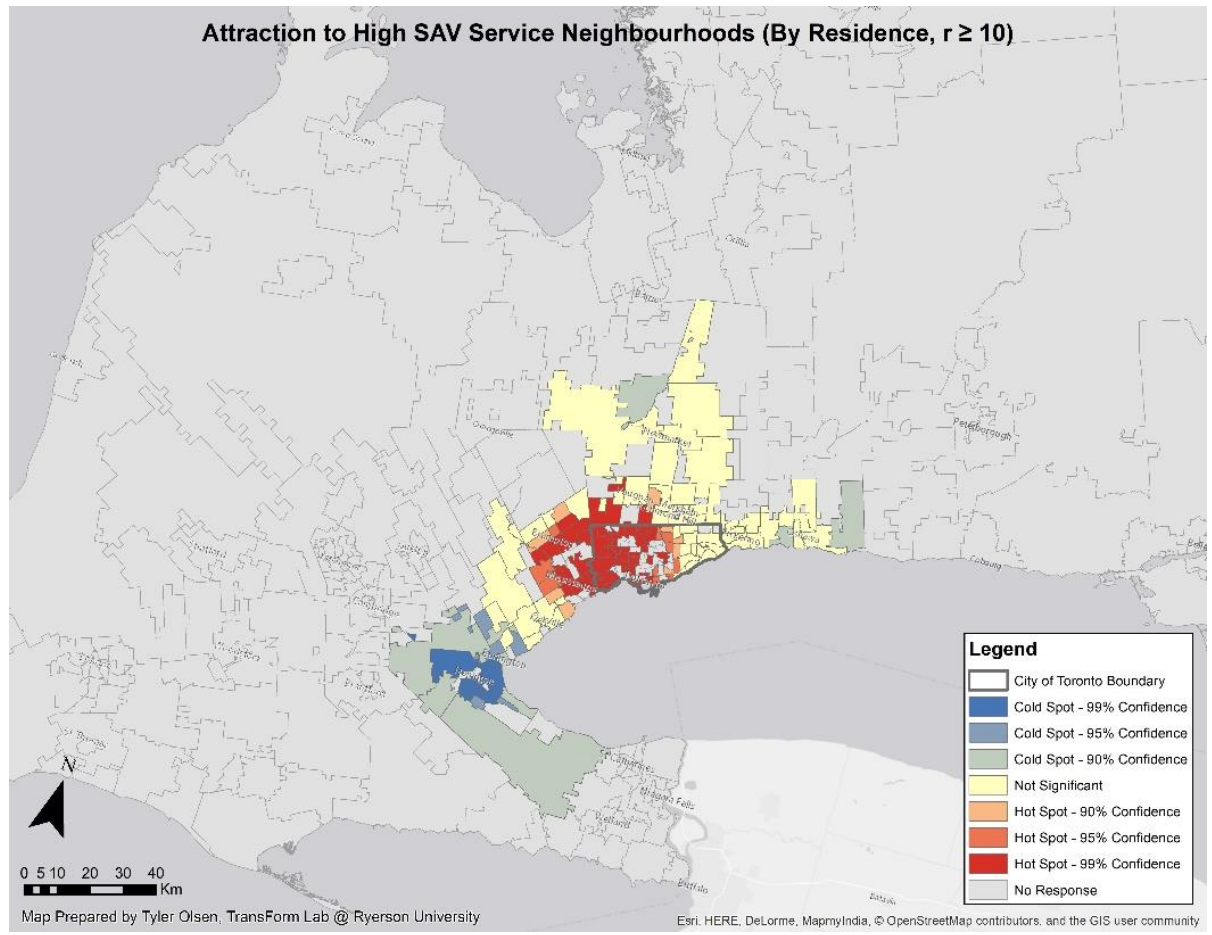

Figure 7

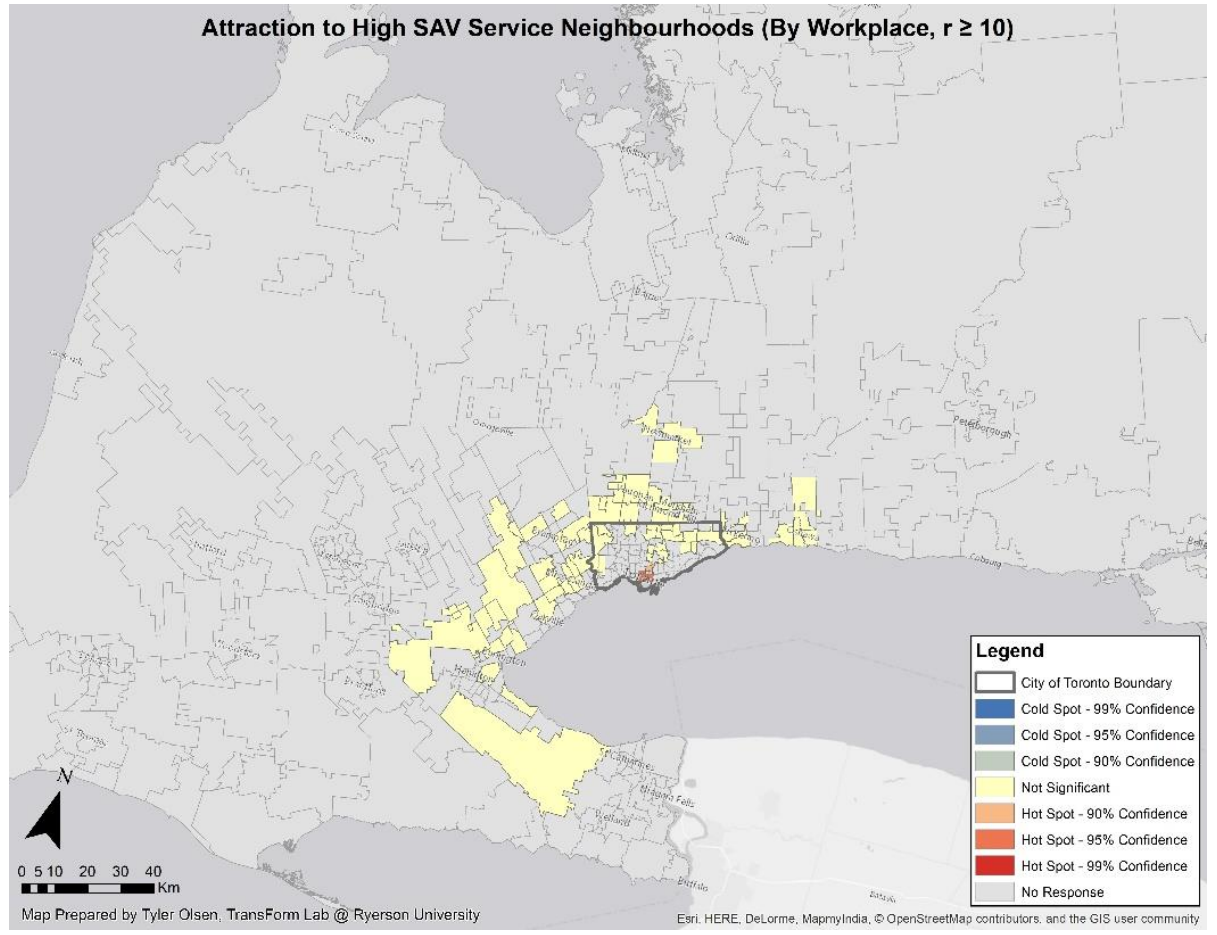


Maps that are not shown did not have significant results and have not been included as they do not present any visual information. In almost all cases, these non-significant results are consistent with the spatial autocorrelation findings (Table 2 and Table 3), which indicated a random arrangement of values-and therefore, no salient pattern to be mapped.

Hot spot analysis in Figure 3 of likelihood to travel further at the same speed (by residence, $r \geq 5$ ) did show significant clustering when mapped, but at a low confidence threshold of $90 \%$. This low confidence, in combination with the slight differences in calculations, likely explains the inconsistency between the hot spot analysis and the random finding in autocorrelation. Further hot spot analysis for attraction to high SAV service neighbourhoods (by work, $r \geq 5$ ) did not indicate clustering, despite the autocorrelation finding. It appears that it was too small a cluster of values, of too few FSAs for the hot spot analysis to identify it as such.

\subsection{Discussion}

From the spatial analysis, there are four high-level insights to underscore.

1) Place of employment does not seem to be related to a spatial patterning of interest in regular use, but place of residence does.

The global spatial autocorrelation measures indicate that there is no clustering of interest in regular use values by place of work. However, there is highly significant clustering of values-greater than $99 \%$ significance-when analyzing by place of residence.

Looking further at the local hot spot analysis, at both FSA respondent thresholds, $r \geq 5$ (Figure 1 ) and $r \geq 10$ (Figure 2), there is a fairly clear pattern of higher than typical interest concentrated in the western half of the Greater Toronto Area: in Peel Region, and the western City of Toronto up to the West Don River Valley. Scarborough and parts of North York are cold spots at the $r \geq 5$ threshold and are notably absent from the high interest cluster at the $r \geq 10$ threshold.

This may have implications for area-specific potential for early adoption and long-term adoption rates. Due to the nature of the survey question asked, though, this is regarding regular use of general AV technology, without specifying SAV or PAV. The survey found that overall $52 \%$ of weight-adjusted respondents indicated interest in regular use of AVs. One could expect the hot spots of interest to have higher than average rates of interest and, as a result, greater potential for early household adoption/use of AV technology when it immediately becomes available and, assuming the same relative distributions of interest remain, higher rates of household adoption/use over the long term. 
To the extent that these areas of elevated interest coincide with hotspots for the following relocation responses, there may be particularly amplified relocation effects, with high rates of $A V$ adoption/use locally, that then feed into tendencies to disperse or concentrate.

2) There is no apparent pattern in potential for dispersal of employment locations.

Global autocorrelation results and local hot spot analysis by employment location found no significant results for responses to either of the "travel further" questions, whether commuting at the same speed or at a higher speed.

The survey found that $35 \%$ of weight-adjusted, employed respondents overall said they were likely to travel further at the same speed, $42 \%$ at a faster speed. No significant clustering means that there is still this potential for dispersal among those responding positively to the question, but the likelihood does not appear to be focused more in one place than another.

3) There is not sufficiently apparent patterning of potential for dispersal at a regional level and only a tenuously apparent local cluster in the western Greater Toronto Area.

At the $r \geq 5$ threshold, global analysis found no spatial pattern in the distribution of likelihood to travel further at the same speed in a driverless vehicle. It found only a very weak clustering in the distribution of likelihood to travel further at a faster speed. In general, this result does not confidently suggest it is not random.

Local hot spot analysis also found marginally significant clustering of likelihood to travel further at the same speed at the $r \geq 5$ threshold (Figure 3) and an only slightly more significant clustering of likelihood to travel further at a faster speed. In both cases, however, the hot spot analysis outlined the cluster similarly to the measure of interest in regular use of AVs: in the western half of the Greater Toronto Area including Peel Region and the western City of Toronto roughly up to the West Don River valley, with notable gaps in the cluster beginning in Scarborough and North York. For the likelihood to travel further at a faster speed, the hot spot cluster even extended to include parts of the Hamilton area.

Survey results indicated that $31 \%$ of weight-adjusted residents overall indicated a likelihood to commute further in an $A V$ at the same speed, $38 \%$ if at a faster speed. In these areas, there may be a weakly elevated potential for residential dispersal-large numbers of residents that choose to make longer commutes, moving out of the area to homes in locations more distant from their work. Further analysis would be necessary to confidently understand whether that is the case.

4) High-quality SAV services are most valued in neighborhoods which are already relatively dense - particularly, residents of the City of Toronto and the western and northern Greater Toronto Area and employees working in downtown Toronto. 
The global analysis found highly significant clustering of attraction to high-quality SAV service neighbourhoods by both place of residence and place of work-in all cases, at all thresholds, at a greater than $99 \%$ significance level. Evidently, there is a clustered spatial pattern to the distribution of attraction to high SAV service neighbourhoods.

Local analysis shows further that higher than typical willingness is clustered across residential neighborhoods in the entire City of Toronto, along with much of Peel and Halton Regions to the west and York Region to the north at the $r \geq 5$ threshold (Figure 5). Durham Region to the east of Toronto, however, is a notable cold spot. At the $r \geq 10$ threshold (Figure 6), there is an observable return of the recurring western GTA cluster: Peel Region and the Western portion of the City of Toronto are part of a cluster of higher than typical residential attraction. Scarborough and North York are again notable exceptions. In terms of employment location, at the $r \geq 10$ threshold (Figure 7), there is a cluster of higher than typical attraction to high SAV service neighbourhoods among workers in downtown Toronto.

The survey results found $35 \%$ of weight-adjusted residents overall expressed attraction, rising to $37 \%$ within the working population. These hot spot areas, then, show potential above and beyond those averages for density to persist or even intensify, contingent on highly effective SAV operations being made available. Populations in these areas show exceptional attraction to neighbourhoods with high SAV service. Where such a high quality service is present-and to the extent that there is inherent advantage in dense urban areas through the economies of scale and greater service frequency-one would expect these populations to remain concentrated or perhaps even concentrate further. Overall, one could expect a stronger tendency towards concentration in the current population in these areas, given the presence of high quality SAV service. Ensuring an effective, early rollout of SAV services in these areas, in particular, may be a tool for advancing policy goals of urban concentration over dispersal, to the extent that growth pattern is still desired.

Overall, there are patterns observable in the arrangement of potential to disperse and concentrate across the Greater Toronto-Hamilton Area, but the reasons for these patterns are unclear. The spatial analysis does not control for the differences in people and places within the underlying geography. In order to understand what is at the core of these trends and, especially, what interventions might be applied to affect them, inferential modelling is applied. 


\subsection{Modelling}

Inferential modelling was used to look deeper at the inner workings of the potential relocation responses. It provides a sense of whether the relocation responses are internally logical and, therefore, realistically feasible. It also allows for the identification of particular characteristics associated with those relocation responses, providing better understanding of possible motivations behind them and to anticipate, in greater detail, other elements that may accompany their outcomes.

With the survey data, it is possible to model the four key questions of interest and estimate predictors of their outcomes. The models are presented in three sections, classified by the general outcome being modelled. These outcomes and the key questions contained within them, are:

\section{$\underline{\text { Interest in Regular Use }}$}

I. Would you be interested in using a driverless car on a regular basis?

\section{Dispersal}

II. Suppose using a driverless vehicle does not enable you to go faster, but enables you to now use that travel time for other activities while traveling. Would you be likely to travel further to work (e.g. for a better job or less expensive housing)?

III. Suppose using a driverless vehicle increases your commuting speed by $25 \%$ and also enables you to now use that time commuting for other activities while traveling. Would you be likely to travel further to work (e.g. for a better job or less expensive housing)?

\section{Concentration}

IV. If some of the GT[H]A's neighborhoods had access to low-cost, near-immediate, and reliable Uberstyle shared driverless vehicle services (like taxis), would such a service make a neighborhood more attractive to you?

For each section, a summary of the results is provided and then detailed results are presented in table form. Results that surpass the $90 \%$ confidence threshold (|t value| > 1.65) are bolded. For reference, results with |t value $\mid>1.96$ and $\mid$ t value | $>2.58$ additionally surpass the $95 \%$ and $99 \%$ thresholds, respectively. Evaluation of potential trends, meaning and insight, where apparent, is drawn out in a general discussion following the results sections. 
The reference case in all of the models - the hypothetical subject that is an aggregation of baseline characteristics against which the effect of other factors is tested-is a:

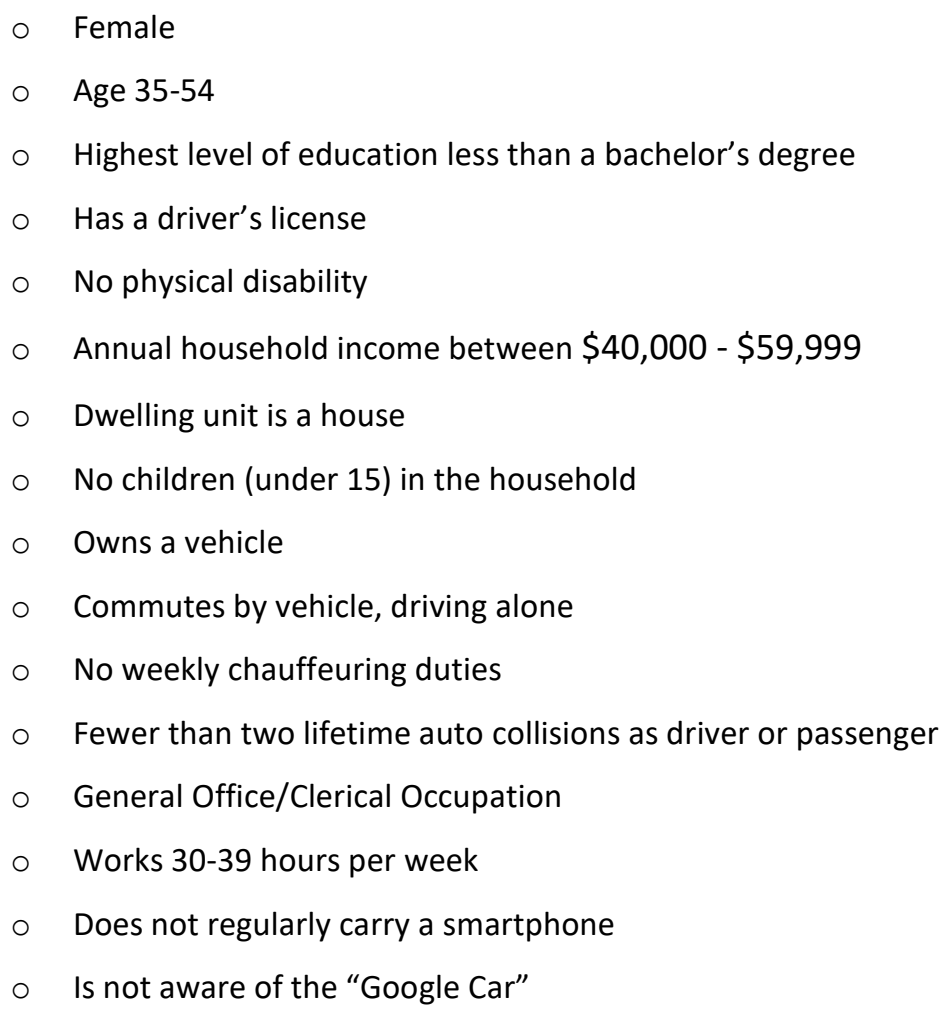

\subsection{Interest in Regular Use}

As shown in Table 4, interest in regular use of AVs is very closely, positively related to being young, being male, having post-secondary education, a high frequency of daily trip making and pre-existing awareness of AV technology. Responding "prefer not to answer" to household income is a highly significant negative predictor but no other income controls are significant. At a slightly lower level of confidence, regularly carrying a smartphone is an additional positive predictor. These results are fairly consistent with the literature, with younger people, males and technological inclinations often associated with greater affinity for AVs (Bansal et al., 2016; Lavasani et al., 2017). 
Table 4. Model Estimates of Interest in Regular Use

\begin{tabular}{|c|c|c|c|}
\hline & \multicolumn{2}{|c|}{ Model I } \\
\hline Variable & Level & Value & T Value \\
\hline \multirow{2}{*}{ Age Group } & $18-34$ & 0.29 & 5.20 \\
\hline & $55-75$ & -0.14 & -1.85 \\
\hline \multirow{2}{*}{ Gender } & Male & 0.23 & 4.35 \\
\hline & Other & -0.01 & -0.02 \\
\hline \multirow{3}{*}{ Highest Education Attained } & Bachelor's Degree & 0.18 & 3.15 \\
\hline & Degree in medicine, dentistry, veterinary medicine or optometry & 0.51 & 2.55 \\
\hline & Graduate Degree (e.g. Master's or Doctoral Degree) & 0.25 & 3.03 \\
\hline Driver's License & No License & 0.02 & 0.14 \\
\hline \multirow{2}{*}{ Has A Physical Disability } & Neither Agree nor Disagree & 0.08 & 0.73 \\
\hline & Does have a physical disability & -0.02 & -0.19 \\
\hline \multirow{8}{*}{ Household Income } & $\$ 0$ to $\$ 14,999$ & -0.28 & -1.14 \\
\hline & $\$ 15,000$ to $\$ 39,999$ & 0.01 & 0.06 \\
\hline & $\$ 60,000$ to $\$ 99,999$ & -0.02 & -0.22 \\
\hline & $\$ 100,000$ to $\$ 124,999$ & -0.11 & -1.07 \\
\hline & $\$ 125,000$ to $\$ 175,000$ & -0.10 & -0.98 \\
\hline & $\$ 175,000$ and above & -0.04 & -0.36 \\
\hline & Prefer not to answer & -0.29 & -2.78 \\
\hline & I don't know & -0.41 & -2.36 \\
\hline \multirow{4}{*}{ Dwelling Unit } & Apartment & -0.04 & -0.62 \\
\hline & Townhouse & 0.09 & 1.10 \\
\hline & Unknown & -1.12 & -1.39 \\
\hline & Other & -0.24 & -1.27 \\
\hline Household Size & [Continuous Logarithmic] & 0.01 & 0.54 \\
\hline Household Members Under 15 & $>0$ & -0.01 & -0.12 \\
\hline Vehicle Ownership & No Vehicle & 0.08 & 0.68 \\
\hline \multirow{8}{*}{ Commute Mode } & Auto driver (with others) & 0.11 & 1.06 \\
\hline & Auto passenger & 0.22 & 1.46 \\
\hline & Taxi/Uber & 0.06 & 0.30 \\
\hline & Walk & 0.11 & 0.77 \\
\hline & Bicycle & -0.13 & -0.47 \\
\hline & GO Transit & 0.16 & 1.36 \\
\hline & Public Transit (excluding GO Transit) & 0.08 & 0.94 \\
\hline & Other & -0.15 & -0.38 \\
\hline Typical Commute Time & [Continuous Logarithmic] & 0.01 & 0.28 \\
\hline Chauffeuring Frequency & $>0$ per Week & 0.08 & 1.30 \\
\hline Collisions as Driver or Passenger & 2 or more & 0.01 & 0.22 \\
\hline Trips Taken Previous Day & $>2$ & 0.14 & 2.63 \\
\hline Population Density in Home FSA & [Continuous Logarithmic] & 0.03 & 1.59 \\
\hline \multirow{4}{*}{ Occupation } & Manufacturing / Construction / Trades & -0.23 & -2.22 \\
\hline & Professional / Management / Technical & 0.02 & 0.26 \\
\hline & Sales and Service & -0.15 & -1.79 \\
\hline & Prefer not to answer & -0.18 & -1.53 \\
\hline \multirow{5}{*}{ Work Hours per Week } & less than 10 hours per week & -0.16 & -1.01 \\
\hline & 10-19 hours per week & 0.16 & 1.40 \\
\hline & 20-29 hours per week & -0.02 & -0.24 \\
\hline & 40-60 hours per week & 0.04 & 0.62 \\
\hline & 60 or more hours per week & 0.24 & 1.61 \\
\hline \multirow{2}{*}{ Regularly Carry a Smartphone } & Yes & 0.24 & 2.29 \\
\hline & Unsure & 0.18 & 0.39 \\
\hline \multirow{2}{*}{ Awareness of Google Car } & Yes & 0.43 & 8.07 \\
\hline & Unsure & 0.25 & 2.72 \\
\hline
\end{tabular}

Model I

Residual Deviance: 5509.501

AIC: 5621.501 


\subsection{Dispersal}

For likelihood to travel further at the same speed in an AV, there are highly significant, positive relationships with being young, male, having a medical-related degree, commuting by walking, having a high frequency of daily tripmaking, regularly carrying a smartphone and being aware of AV technology. Being older and preferring not to answer the household income question are highly significant, negative predictors. There are less significant potential positive associations with commuting as a carpool driver, having weekly chauffeuring duties and working

fewer than 10 hours per week or $40-60$ hours per week. Having a household income of $\$ 0$ to $\$ 14,999$ is negatively associated at this lower significance as well.

When a faster speed is combined with the choice to take on a longer commute, the story is somewhat similar. Being young, a carpool driver commuter, frequent trip taker, regularly carrying a smartphone and having an awareness of $A V s$ have positive, highly significant relationships; being older and providing an indeterminate response to household income have negative ones. To a lesser significance, being male, having a medical-related degree and being a pedestrian commuter are associated with increased likelihood to travel further; not owning a vehicle and being a cycling commuter have the opposite effect.

In both dispersal responses, the young, male, technologically-savvy factors emerge here as positive predictors, similar to other studies' findings for expectations to relocate and disperse (Bansal et al., 2016; Lavasani et al., 2017). High frequency of daily trips and being a pedestrian or carpool driver commuter are also consistent, significant positive predictors for potential dispersal. The only notable difference the speed seems to make is that work hours (less than 10 and 40-60 per week) are not as significant predictors with faster travel. This seems counter-intuitive and the reasons for this finding are unclear: if time is the primary concern, why would faster travel not be even more significantly related to work hours? This is a finding ripe for further inquiry. 
Table 5. Model Estimates of Likelihood to Travel Further at Same Speed (Model II) and Faster Speed (Model III)

\begin{tabular}{|c|c|c|c|c|c|}
\hline \multirow[b]{2}{*}{ Variable } & \multirow[b]{2}{*}{ Level } & \multicolumn{2}{|c|}{ Model II } & \multicolumn{2}{|c|}{ Model III } \\
\hline & & Value & T Value & Value & T Value \\
\hline \multirow{2}{*}{ Age Group } & $18-34$ & 0.23 & 3.72 & 0.26 & 4.00 \\
\hline & $55-75$ & -0.38 & -4.21 & -0.36 & -4.07 \\
\hline \multirow{2}{*}{ Gender } & Male & 0.16 & 2.80 & 0.13 & 2.16 \\
\hline & Other & -0.25 & -0.48 & -0.31 & -0.57 \\
\hline \multirow{3}{*}{ Highest Education Attained } & Bachelor's Degree & 0.09 & 1.42 & 0.11 & 1.73 \\
\hline & $\begin{array}{l}\text { Degree in medicine, dentistry, veterinary } \\
\text { medicine or optometry }\end{array}$ & 0.91 & 3.93 & 0.53 & 2.31 \\
\hline & Graduate Degree (e.g. Master's or Doctoral) & 0.12 & 1.33 & 0.07 & 0.76 \\
\hline Driver's License & No License & -0.15 & -1.10 & 0.07 & 0.48 \\
\hline \multirow{2}{*}{ Has A Physical Disability } & Neither Agree nor Disagree & -0.20 & -1.65 & -0.23 & -1.93 \\
\hline & Does have a physical disability & -0.05 & -0.50 & -0.15 & -1.39 \\
\hline \multirow{8}{*}{ Household Income } & $\$ 0$ to $\$ 14,999$ & -0.72 & -2.13 & -0.65 & -1.91 \\
\hline & $\$ 15,000$ to $\$ 39,999$ & 0.06 & 0.49 & 0.05 & 0.39 \\
\hline & $\$ 60,000$ to $\$ 99,999$ & 0.04 & 0.43 & 0.03 & 0.27 \\
\hline & $\$ 100,000$ to $\$ 124,999$ & -0.18 & -1.60 & -0.09 & -0.79 \\
\hline & $\$ 125,000$ to $\$ 175,000$ & -0.18 & -1.58 & -0.11 & -0.97 \\
\hline & $\$ 175,000$ and above & -0.11 & -0.94 & -0.16 & -1.31 \\
\hline & Prefer not to answer & -0.35 & -2.90 & -0.41 & -3.39 \\
\hline & I don't know & -0.32 & -1.62 & -0.53 & -2.63 \\
\hline \multirow{4}{*}{ Dwelling Unit } & Apartment & 0.05 & 0.63 & 0.08 & 1.05 \\
\hline & Townhouse & -0.01 & -0.10 & -0.14 & -1.52 \\
\hline & Unknown & 0.22 & 0.27 & 0.75 & 0.94 \\
\hline & Other & -0.30 & -1.37 & -0.34 & -1.58 \\
\hline Household Size & [Continuous Logarithmic] & -0.01 & -0.30 & 0.03 & 1.31 \\
\hline Household Members Under 15 & $>0$ & -0.07 & -1.05 & -0.08 & -1.19 \\
\hline Vehicle Ownership & No Vehicle & -0.01 & -0.05 & -0.29 & -2.16 \\
\hline \multirow{8}{*}{ Commute Mode } & Auto driver (with others) & 0.24 & 2.01 & 0.33 & 2.63 \\
\hline & Auto passenger & 0.09 & 0.51 & 0.24 & 1.38 \\
\hline & Taxi/Uber & -0.01 & -0.04 & -0.27 & -1.04 \\
\hline & Walk & 0.45 & 2.81 & 0.39 & 2.39 \\
\hline & Bicycle & -0.65 & -1.76 & -0.86 & -2.15 \\
\hline & GO Transit & 0.10 & 0.73 & 0.16 & 1.17 \\
\hline & Public Transit (excluding GO Transit) & 0.11 & 1.24 & 0.13 & 1.39 \\
\hline & Other & 0.03 & 0.07 & 0.08 & 0.17 \\
\hline Typical Commute Time & [Continuous Logarithmic] & 0.03 & 0.92 & 0.06 & 1.57 \\
\hline Chauffeuring Frequency & $>0$ per Week & 0.14 & 2.05 & 0.12 & 1.72 \\
\hline Collisions as Driver or Passenger & 2 or more & -0.06 & -1.11 & 0.03 & 0.56 \\
\hline Trips Taken Previous Day & $>2$ & 0.19 & 3.15 & 0.20 & 3.32 \\
\hline Population Density in Home FSA & [Continuous Logarithmic] & 0.00 & 0.10 & 0.01 & 0.57 \\
\hline \multirow{4}{*}{ Occupation } & Manufacturing / Construction / Trades & -0.04 & -0.30 & -0.14 & -1.16 \\
\hline & Professional / Management / Technical & 0.07 & 0.88 & 0.14 & 1.80 \\
\hline & Sales and Service & -0.03 & -0.36 & -0.04 & -0.47 \\
\hline & Prefer not to answer & 0.03 & 0.25 & -0.08 & -0.61 \\
\hline \multirow{5}{*}{ Work Hours per Week } & less than 10 hours per week & 0.38 & 2.03 & 0.15 & 0.80 \\
\hline & 10-19 hours per week & -0.02 & -0.16 & -0.02 & -0.19 \\
\hline & 20-29 hours per week & 0.14 & 1.16 & 0.03 & 0.29 \\
\hline & 40-60 hours per week & 0.15 & 2.33 & 0.12 & 1.90 \\
\hline & 60 or more hours per week & 0.20 & 1.23 & 0.23 & 1.40 \\
\hline \multirow{2}{*}{ Regularly Carry a Smartphone } & Yes & 0.48 & 3.69 & 0.42 & 3.22 \\
\hline & Unsure & 0.86 & 1.70 & -0.03 & -0.06 \\
\hline \multirow{2}{*}{ Awareness of Google Car } & Yes & 0.23 & 3.83 & 0.21 & 3.37 \\
\hline & Unsure & 0.20 & 1.97 & 0.27 & 2.64 \\
\hline
\end{tabular}



Model II
Residual Deviance: 3634.171
AIC: 3742.171
Model III
Residual Deviance: 3530.285
AIC: 3638.285

\subsection{Concentration}

In the final model, estimating attractiveness to high SAV service neighbourhoods, again being young, male, techsavvy and aware of AVs are highly significant and positive factors. But, in notable addition, being a public transit commuter is also highly significant and positively associated. As well, an interesting land-use variable emerges to significance for the first time: as population density of a respondent's home neighbourhood increases, so does the likelihood of being attracted to a high SAV service neighbourhood. At lower significance, taking more trips daily and working more than 60 hours per week are positively associated. Preferring not to answer the household income question is negatively associated. 
Table 6. Model Estimates of Attraction to High SAV Service Neighbourhoods

\begin{tabular}{|c|c|c|c|}
\hline \multirow[b]{2}{*}{ Variable } & \multirow[b]{2}{*}{ Level } & \multicolumn{2}{|c|}{ Model IV } \\
\hline & & Value & T Value \\
\hline \multirow{2}{*}{ Age Group } & $18-34$ & 0.35 & 5.86 \\
\hline & $55-75$ & -0.07 & -0.92 \\
\hline \multirow{2}{*}{ Gender } & Male & 0.15 & 2.64 \\
\hline & Other & -0.08 & -0.17 \\
\hline \multirow{3}{*}{ Highest Education Attained } & Bachelor's Degree & 0.08 & 1.31 \\
\hline & Degree in medicine, dentistry, veterinary medicine or optometry & 0.15 & 0.73 \\
\hline & Graduate Degree (e.g. Master's or Doctoral Degree) & 0.16 & 1.82 \\
\hline Driver's License & No License & -0.08 & -0.64 \\
\hline \multirow{2}{*}{ Has A Physical Disability } & Neither Agree nor Disagree & -0.20 & -1.79 \\
\hline & Does have a physical disability & 0.17 & 1.70 \\
\hline \multirow{8}{*}{ Household Income } & $\$ 0$ to $\$ 14,999$ & -0.06 & -0.20 \\
\hline & $\$ 15,000$ to $\$ 39,999$ & -0.01 & -0.05 \\
\hline & $\$ 60,000$ to $\$ 99,999$ & -0.04 & -0.42 \\
\hline & $\$ 100,000$ to $\$ 124,999$ & -0.15 & -1.45 \\
\hline & $\$ 125,000$ to $\$ 175,000$ & -0.13 & -1.23 \\
\hline & $\$ 175,000$ and above & -0.03 & -0.22 \\
\hline & Prefer not to answer & -0.23 & -2.09 \\
\hline & I don't know & -0.24 & -1.36 \\
\hline \multirow{4}{*}{ Dwelling Unit } & Apartment & -0.02 & -0.27 \\
\hline & Townhouse & -0.13 & -1.48 \\
\hline & Unknown & 0.32 & 0.43 \\
\hline & Other & -0.11 & -0.55 \\
\hline Household Size & [Continuous Logarithmic] & -0.04 & -1.65 \\
\hline Household Members Under 15 & $>0$ & 0.01 & 0.17 \\
\hline Vehicle Ownership & No Vehicle & 0.09 & 0.77 \\
\hline \multirow{8}{*}{ Commute Mode } & Auto driver (with others) & 0.19 & 1.63 \\
\hline & Auto passenger & 0.18 & 1.10 \\
\hline & Taxi/Uber & -0.05 & -0.20 \\
\hline & Walk & 0.28 & 1.82 \\
\hline & Bicycle & 0.26 & 0.86 \\
\hline & GO Transit & 0.16 & 1.27 \\
\hline & Public Transit (excluding GO Transit) & 0.27 & 3.11 \\
\hline & Other & -0.35 & -0.86 \\
\hline Typical Commute Time & [Continuous Logarithmic] & 0.03 & 0.94 \\
\hline Chauffeuring Frequency & $>0$ per Week & 0.13 & 2.07 \\
\hline Collisions as Driver or Passenger & 2 or more & 0.01 & 0.25 \\
\hline Trips Taken Previous Day & $>2$ & 0.12 & 2.14 \\
\hline Population Density in Home FSA & [Continuous Logarithmic] & 0.06 & 2.87 \\
\hline \multirow{4}{*}{ Occupation } & Manufacturing / Construction / Trades & 0.21 & 1.88 \\
\hline & Professional / Management / Technical & 0.09 & 1.25 \\
\hline & Sales and Service & 0.00 & -0.04 \\
\hline & Prefer not to answer & 0.01 & 0.12 \\
\hline \multirow{5}{*}{ Work Hours per Week } & less than 10 hours per week & 0.07 & 0.42 \\
\hline & 10-19 hours per week & -0.03 & -0.22 \\
\hline & 20-29 hours per week & -0.14 & -1.32 \\
\hline & 40-60 hours per week & 0.03 & 0.43 \\
\hline & 60 or more hours per week & 0.33 & 2.11 \\
\hline \multirow{2}{*}{ Regularly Carry a Smartphone } & Yes & 0.40 & 3.49 \\
\hline & Unsure & 0.55 & 1.10 \\
\hline \multirow{2}{*}{ Awareness of Google Car } & Yes & 0.21 & 3.70 \\
\hline & Unsure & 0.21 & 2.17 \\
\hline
\end{tabular}

Model IV

Residual Deviance: 4068.278

AIC: 4176.278 


\subsection{Discussion}

Overall, looking across the models, fairly similar demographic factors seem to be inclined towards both potential dispersal and concentration responses: young, male, and some form of post-secondary education.

Land use is not generally a significant factor among the variables with one exception: population density for area of residence is significant for attraction to high service SAV neighbourhoods. This suggests that the people that currently live in denser areas-which based on preliminary research is taken to be the environment most conducive to high-quality SAV service (Loeb et al., 2018; Milakis et al., 2017)-are the same people more likely to be interested to use these SAV services. Ensuring the presence of an effective SAV service would, thus, seem to reinforce the existing balance of neighbourhood selection and locations of concentration and density. Here, again, SAVs present themselves as a promising tool for preserving existing population concentration.

Regarding travel behaviour, commute duration remarkably does not seem to matter, but number of daily trips consistently does, being a significant, positive predictor of all potential relocation responses. From this data it appears that possibilities for relocation presented by AVs may not appeal so much to those that have lengthy commutes, but instead appeal to those that take many trips. Both of the travel further questions suggest potential to draw on pedestrian commuters, perhaps turning some trips within this active mode share into automobilebased ones. The SAV neighbourhood question indicates a strong affinity with pedestrian and transit commuters. In concert, these findings suggest that there appears to be potential for travel behaviour change among active and transit commuters, but the precise types of changes and balance of concentrating and/or dispersing forces remains to be tested. 


\subsection{Conclusion}

Through the analysis of 2016 survey data, this study explored respondents' stated preferences regarding the potential relocation of their work or residence in response to AVs, to understand the locations and characteristics of those with different responses and the potential impacts on land use that may result. Overall, there are four general insights to highlight.

\section{There is a recurring spatial pattern of interest and concentration responses}

Spatial analysis found that, residentially, interest in regular use of AVs does seem to be distinctly clustered in the western GTA, including Peel Region and the western City of Toronto. There is still an underlying potential among respondents towards longer commutes and dispersal (with $31 \%$ of respondents interested to do so if $A V s$ run at the same speed, $38 \%$ if at a faster speed), but it does not appear that it would affect one place more than another. There is, however, a strong indication that the City of Toronto, along with the western and northern GTA, is a cluster of remarkable residential attraction to high-quality SAV service neighbourhoods. Downtown Toronto is a significant center of worker interest in these types of neighbourhoods.

2. Modelling analysis showed that there is a fairly consistent profile that tends towards both potential dispersal and concentration responses

This profile is young, male, some form of post-secondary education, tech-savvy, with a high daily trip making frequency. Attraction to high-quality SAV service neighbourhoods is positively, significantly associated with residential population density. The spatial distribution of these characteristics may explain some of the underlying causes for the spatial pattern, but further research is needed.

3. There are indications that ensuring the presence of high-quality SAV service may reinforce the existing concentration of residences

Insofar that high quality SAV service is likely to be best delivered in dense areas with large internal markets of trip origins and destinations, then findings suggest that ensuring high-quality SAV service could reinforce existing concentration. The people that currently live in denser areas-which, based on preliminary research, are taken to be the environment most conducive to high quality SAV service-are the same people interested to use these SAV services. Ensuring the presence of an effective SAV service could, thus, reinforce the existing balance of neighbourhood selection and locations of residential concentration and density.

To the extent that preserving or expanding the GPGGH's vision of population concentrations is desired, this creates a potential case for public intervention. Through incentives, partnerships and/or regulation, ensuring the execution of high-quality SAV service-in particular, in the hot spots identified for attraction to high-quality SAV 
neighbourhoods-could ensure that AV use complements rather than undermines residential and employment location in dense, existing neighbourhoods.

4. There is apparent potential for $A V s$, in private or shared format, to disrupt the travel mode-based objectives of the GPGGH

There are indications that both pedestrians and transit users - two mode share groups explicitly preferred by the GPGGH - appear to be most inclined towards behavioural change in response to AVs. The magnitude and direction of these behavioural changes should be further explored. To the extent the potential shift of these groups away from current travel behaviours is undesired, travel demand management techniques could be deployed, although that could then interfere with the possibility of SAVs to act as a concentrating force. This creates a challenging premise: in an AV world, the GPGGH's land use and mode share-based objectives may be challenged-perhaps even set at odds to each other-by the diverse array of behavioural responses to this new technology and to the business models likely to emerge in its wake. Further consideration may be needed to decide whether the plan should be revisited, to consider how AVs fit into its travel mode objectives or how the plan can remain flexible to be able to respond to this uncertainty. 


\section{References}

Allen, R. \& Campsie, P. (2013). Implementing the Growth Plan for the Greater Golden Horseshoe. Toronto: Neptis Foundation.

Anderson, J., Kalra, N., Stanley, K., Sorenson, P., Samaras, C., Oluwatola, O. (2014). Autonomous Vehicle Technology: A Guide for Policymakers. Washington, D.C.: RAND Corporation.

Bansal, P., Kockelman, K. M., \& Singh, A. (2016). Assessing public opinions of and interest in new vehicle technologies: an Austin perspective. Transportation Research Part C: Emerging Technologies, 67, 1-14.

Bansal, P., \& Kockelman, K. M. (2017). Forecasting Americans' long-term adoption of connected and autonomous vehicle technologies. Transportation Research Part A: Policy and Practice, 95, 49-63.

Begg, D. (2014). A 2050 Vision for London: What are the Implications of Driverless Transport. Retrieved from: http://www.transporttimes.co.uk/Admin/uploads/64165-Transport-Times A-2050-Vision-forLondon_AWWEB-READY.pdf (February 15, 2018).

Birnbaum, L., Sweet, M., Comeau, E., Olsen, T. (2017). Driverless Cars in the Greater Toronto and Hamilton Area: Focus group findings. Toronto: Ryerson University.

Bloomberg Philanthropies \& The Aspen Institute. (2017). Taming the Autonomous Vehicle: A Primer for Cities. Long Island City, NY.

Courtney, K. (2009). Sustainable Urban Transportation And Ontario's New Planning Regime: The Provincial Policy Statement, 2005 and the Growth Plan for the Greater Golden Horseshoe. Journal of Environmental Law and Practice. 19 (2). 71-104.

Environmental Systems Research Institute. (2017a). How Hot Spot Analysis (Getis-Ord Gi*) Works. Retrieved from: http://pro.arcgis.com/en/pro-app/tool-reference/spatial-statistics/h-how-hot-spot-analysis-getis-ord-gispatial-stati.htm (March 1, 2018).

Environmental Systems Research Institute. (2017b). How Spatial Autocorrelation (Global Moran's I) Works. Retrieved from: http://pro.arcgis.com/en/pro-app/tool-reference/spatial-statistics/h-how-spatialautocorrelation-moran-s-i-spatial-st.htm (March 1, 2018).

KPMG. (2013). Self-Driving Cars: Are We Ready? Retrieved from: http://www.kpmginstitutes.com/content/dam/kpmg/manufacturing-institute/pdf/2017/self-driving-cars-are-we-ready.PDF (February 6, 2018). 
Krueger, R., Rashidi, T.H., Rose, J.M. (2016). Preferences for shared autonomous vehicles. Transportation Research Part C. 69. 343-355.

Kyriakidis, M., Happee, R., de Winter, J.C.F. (2015). Public opinion on automated driving: Results of an international questionnaire among 5000 respondents. Transportation Research Part F: Traffic Psychology and Behaviour. 32. 127-140.

Laidlaw, K., \& Sweet, M. (2017). Estimating Consumer Demand for Autonomous Vehicles in the Greater TorontoHamilton Area: 2016 Survey and Model Results. TRB 96 ${ }^{\text {th }}$ Annual Meeting.

Laidlaw, K., Sweet M., Olsen, T. (2018). Forecasting the Outlook for Automated Vehicles in the Greater Toronto and Hamilton Area using a 2016 Consumer Survey. Toronto: Ryerson University.

Lavasani, M., Asgari, H., Jin X., Pinjari, A. (2017). Investigating the willingness to pay for autonomous vehicles and the likelihood of residential relocation. TRB $96^{\text {th }}$ Annual Meeting.

Litman, T. (2015). Autonomous Vehicle Implementation Predictions. Victoria Transport Policy Institute, 28.

Loeb, B., Kockelman, K., Liu, J. (2018). Shared autonomous electric vehicle (SAEV) operations across the Austin, Texas network with charging infrastructure decisions. Transportation Research Part C: Emerging Technologies. 89. 222-233.

Lustgarten, P., \& Le Vine, S. (2017). Public priorities and consumer preferences for selected attributes of automated vehicles. Journal of Modern Transport, 1-8.

Milakis, D., van Arem, B., van Wee B. (2017). Policy and society related implications of automated driving: A review of literature and directions for future research. Journal of Intelligent Transportation Systems. 1-24

Ministry of Municipal Affairs. (2017). Growth Plan for the Greater Golden Horseshoe. Toronto: Queen's Printer for Ontario.

Newbold, K., Scott, D. (2013). Migration, commuting distance, and urban sustainability in Ontario's Greater Golden Horseshoe: Implications of the Greenbelt and Places to Grow legislation. The Canadian Geographer. 57(4). 474-487.

Olsen, T., Laidlaw, K., \& Sweet, M. (2018). Automated Vehicles in the Greater Toronto-Hamilton Area: Overview from a 2016 Consumer Survey Part B: Data Overview. Toronto: Ryerson University. 
Schoettle, B., \& Sivak, M. (2014). Public Opinion about Self-Driving Vehicles in China, India, Japan, The U.S., The U.K., and Australia. Ann Arbor: The University of Michigan Transportation Research Institute.

Standing Senate Committee on Transport and Communications. (2018). Driving Change: Technology and the future of the automated vehicle. Retrieved from:

https://sencanada.ca/content/sen/committee/421/TRCM/Reports/COM_RPT_TRCM_AutomatedVehicles e.pdf (February 18, 2018).

White, R. (2007). The Growth Plan for the Greater Golden Horseshoe in historical perspective. Toronto: Neptis Foundation.

WSP Global Inc. (2016). New Mobility. Report commissioned for Metrolinx. August, 2016.

WSP Global Inc. (2017). New Mobility Now: A Practical Guide.

Zmud, J., Sener, I., \& Wagner, J. (2016). Revolutionizing Our Roadways Consumer Acceptance and Travel Behavior Impacts of Automated Vehicles. College Station: Texas A\&M.

Zon, N. \& Ditta, S. (2016). Robot, take the wheel: Public policy for automated vehicles. Toronto: Mowat Research. 